\title{
Detecção de fatores de virulência em estirpes de Campylobacter spp. isoladas de carcaças de suínos abatidos em frigoríficos
}

\author{
[Virulence factors in strains of Campylobacter spp. isolated from the carcasses of swine \\ slaughtered in abattoirs] \\ G.O. Silva ${ }^{1}$, A.F. Carvalho ${ }^{2}$, S. Miyashiro ${ }^{2}$, A.F.C. Nassar ${ }^{2}$, R.M. Piatti ${ }^{2}$, E. Scarcelli ${ }^{*}$ \\ ${ }^{1}$ Aluna de Pós-Graduação - Instituto Biológico - São Paulo, SP \\ ${ }^{2}$ Instituto Biológico - São Paulo, SP
}

\begin{abstract}
RESUMO
Isolaram-se estirpes de Campylobacter spp. em amostras de carcaças $(n=65)$, fezes $(n=65)$ e linfonodos mesentéricos $(\mathrm{n}=65)$ de suínos abatidos em frigoríficos do estado de São Paulo e detectaram, pela técnica da Multiplex-PCR, a presença do complexo de genes $c d t$, responsáveis pela expressão do fator de virulência da toxina CDT. Do total de 195 amostras de origem suína, Campylobacter spp. foi isolado de $31(15,9 \%)$, sendo $29(93,6 \%)$ de amostras de suabe retal, 1/65 (3,2\%) de suabe de carcaça e um $(3,2 \%)$ de linfonodo. Vinte e oito estirpes de $C$. coli foram positivas para a detecção dos genes $c d t$, e três estirpes de $C$. jejuni foram negativas para a detecção desses genes. Foi detectada, pela primeira vez no estado de São Paulo, a presença dos genes $c d t$ em $100 \%$ das estirpes de Campylobacter coli provenientes de suínos abatidos em frigoríficos.
\end{abstract}

Palavras-chave: suíno, Campylobacter coli, abatedouro, toxina citoletal distensiva, CDT

\begin{abstract}
The purposes of this study were to isolate and identify Campylobacter spp. strains from the carcasses $(n=65)$, feces $(n=65)$ and mesenteric lymph nodes $(n=65)$ of swine slaughtered in abattoirs in the State of Sao Paulo and to detect the presence of the cdt gene complex - responsible for the expression of the virulence factor cytolethal distensive toxin - in these Campylobacter spp. strains through Multiplex-PCR. From 195 samples analyzed, Campylobacter spp. was isolated in 31 (15.9\%): 29 (93,6\%) samples of rectal swab, 1 (3.2\%) carcass swab and 1 (3.2\%) lymph node sample. The 28 strains of isolated $\mathrm{C}$. coli were positive for CDT toxin genes and the three strains of isolated $\mathrm{C}$. jejuni were negative for these genes. It was also the first time that the cdt gene cluster was detected in strains isolated from swine in the state of São Paulo. These findings indicate swine as a potential spreading source of virulent strains of Campylobacter coli, either for slaughterhouse staff or consumers of carcasses and sub products.
\end{abstract}

Key words: Swine, Campylobacter coli, abattoir, cytolethal distensive toxin, CDT

\section{INTRODUÇÃO}

Os setores do agronegócio paulista que apresentaram o maior crescimento nas exportações em 2008, comparado ao ano de 2007, foram os de suínos e aves $(49,7 \%$, para US\$ 570 milhões), segundo estudo do Instituto de Economia Agrícola (IEA-APTA), vinculado à Secretaria de Agricultura e Abastecimento
(Agência..., 2009). Na Europa, a produção de carne destaca-se como uma das maiores atividades, sendo a carne suína $(48,7 \%)$ o principal tipo comercializado, seguida pela carne de frango $(23,6 \%)$ e pela bovina $(23,3 \%)$. A produção de carne de ovinos, caprinos, equinos e coelhos corresponde somente a um pequeno percentual do total produzido (Mataragas et al., 2008).

Recebido em 15 de abril de 2011

Aceito em 24 de maio de 2012

*Autor para correspondência (corresponding autor)

E-mail: pinheiro@biologico.sp.gov.br 
Campylobacter spp. coloniza o trato gastrintestinal de várias espécies domésticas e selvagens, principalmente aquelas destinadas ao consumo humano (Malakauskas et al., 2005). Campylobacter spp. é observado no trato intestinal de suínos, sendo a espécie Campylobacter coli a mais comumente isolada. Carcaças de suínos são mais frequentemente contaminadas por Campylobacter do que carcaças de bovinos e ovinos. Entretanto, tem sido relatadas taxas de contaminação variando de $2,9 \%$ na Polônia a $95 \%$ na Suécia (Nesbakken et al., 2003).

No Brasil, C. coli e C. jejuni e, com menor frequência, $C$. fetus subsp. fetus têm sido isolados de carcaças e fezes de suínos aparentemente sadios abatidos em abatedouros, como também de animais com sintomas clínicos de distúrbios entéricos manifestados sob forma de diarreia (Scarcelli et al., 1991, 1998; Campos, 2007; Gabriel et al., 2010). No país, ainda são poucos os relatos de surtos em humanos, e a campilobacteriose intestinal permanece pouco descrita, ou seja, subnotificada (Scarcelli et al., 2005; Calil et al., 2008). Segundo dados da Secretaria de Vigilância em Saúde (SVS), entre 1999 e 2008 foram notificados no território nacional 6062 surtos de doenças transmissíveis por alimentos (DTA), sendo o Campylobacter spp. classificado entre os agentes menos frequentes e responsabilizado por apenas quatro surtos (Brasil, 2008).

A campilobacteriose é uma zoonose de distribuição mundial, em que o gênero Campylobacter está amplamente distribuído na natureza, pois já foi isolado de diversas espécies domésticas e silvestres, assim como no homem (Altekruse, 1998; Scarcelli et al., 1998, 2005). Atribui-se a transmissão para o ser humano ao contato direto com animais portadores, ao consumo de água e alimentos de origem animal e vegetal contaminados, carnes de aves, suínos ou bovinos malprocessadas, e à ingestão de leite não pasteurizado (Kumar et al., 2001; Saito et al., 2005; Scarcelli et al., 2005; Peyrat et al., 2008).

Um dos principais fatores de virulência relacionados à patogênese do Campylobacter spp. (C. coli, C. fetus, C. jejuni e C. lari) em infecções animais e humanas é denominado toxina citoletal distensiva (CDT), codificada pelos genes adjacentes $c d t \mathrm{~A}, c d t \mathrm{~B}$ e $c d t \mathrm{C}$
(Martinez et al., 2006). A toxina interfere na divisão e diferenciação das células das criptas intestinais, levando ao desenvolvimento da diarreia (Park, 2002). A proteína produzida pelo gene $c d t B(\mathrm{CdtB})$ potencializa o bloqueio do ciclo celular, e as proteínas dos genes $c d t A$ e $c d t C$ funcionam como subunidades diméricas, que transportam a proteína do $\mathrm{CdtB}$ e a interiorizam na célula hospedeira (Martinez et al., 2006; Asakura et al., 2008).

O presente trabalho teve por objetivos: isolar e identificar, por métodos fenotípicos e genotípicos, estirpes de Campylobacter spp. de amostras de carcaças, fezes e linfonodos mesentéricos de suínos abatidos em dois frigoríficos localizados no estado de São Paulo, bem como detectar pela primeira vez nestes suínos, pela técnica da Multiplex-PCR, estirpes de Campylobacter spp. portadoras do complexo de genes $c d t$ responsável pela expressão do fator de virulência da toxina citoletal distensiva (CDT).

\section{MATERIAL E MÉTODOS}

Foram colhidas, entre 2008 e 2009, 195 amostras originárias de suínos abatidos em dois frigoríficos localizados no estado de São Paulo: o primeiro denominado abatedouro A, com Serviço de Inspeção Federal, e o segundo abatedouro B, com Serviço de Inspeção Estadual, ambos com capacidade de abate/dia de mais de 300 animais. Do abatedouro A, foram colhidas 45 amostras, e do abatedouro B 135 amostras.

As amostras consistiam de 65 suabes de carcaças - esfregaço das regiões dorsal e lateral do lado interno da carcaça -, 65 suabes retais e 65 linfonodos mesentéricos. Os suabes de carcaças e retais foram introduzidos em tubos contendo $3 \mathrm{~mL}$ de meio Brain Heart Infusion (BHI Difco), e os linfonodos em sacos plásticos estéreis (Nasco). Todas as amostras foram transportadas até o laboratório em caixas isotérmicas, com gelo reciclável, à temperatura de até $8^{\circ} \mathrm{C}$. As amostras foram submetidas ao procedimento bacteriológico para isolamento e identificação bioquímica de Campylobacter spp., segundo Scarcelli et al. (1998) e World Organisation for Animal Health OIE (2008). A susceptibilidade aos antibióticos, ácido nalidíxico e cefalotina, seguiram a metodologia 
de difusão com discos, National Committee for Clinical Laboratory Standards (NCCLS, 2003).

Das estirpes de Campylobacter spp. extraiu-se o DNA por meio do kit comercial Ilustra Bacterial Genomic PREP Mini Spin (GE Healthcare), segundo especificações do fabricante. Visando confirmar pela PCR a triagem inicial realizada pelas provas bioquímicas, foi pesquisada a presença do gene hip relacionada ao $C$. jejuni, codificante da enzima hipuricase, que corresponde a um fragmento de $735 \mathrm{pb}$, cujos oligonucleotídeos iniciadores empregados foram: HIP400F 5'-GAA GAG GGT TTG GGT GGT G-3' e HIP1134R 5'-AGC TAG CTT CGC ATA ATA ACT TG-3' (Invitrogen). Para as amostras de $C$. coli, foi pesquisado o gene da aspartoquinase, que corresponde a um fragmento de $500 \mathrm{pb}$, cujos oligonucleotídeos iniciadores empregados foram: CC18F 5'-GGT ATG ATT TCT ACA AAG CGA G-3' e CC519R 5'-ATA AAA GAC TAT CGT CGC GTG-3' (Invitrogen)
(Linton et al., 1997). Como controles positivos foram utilizadas estirpes padrão de Campylobacter jejuni ATCC 33291 e Campylobacter coli CDC A3315.

A análise dos produtos amplificados foi realizada por eletroforese em gel de agarose (Invitrogen) a $2,0 \%$. Os géis foram corados por brometo de etídeo $(0,5 \mu \mathrm{g} / \mathrm{mL})$ (Invitrogen) e posteriormente fotografados sob luz ultravioleta (300-320nm) pelo sistema de fotodocumentação, Câmera Kodak Digital DC/120 Zoom, e analisados com o software 1D Image Analysis (Kodak Digital Science).

O DNA das estirpes de $C$. jejuni $e$ C. coli extraído anteriormente foi submetido à técnica da Multiplex-PCR com primers (Invitrogen) e metodologia descritos por Asakura et al. (2008) para detecção dos genes $c d t A, c d t B$ e $c d t C$ (Tab. 1).

Tabela 1. Sequência nucleotídica dos primers para Campylobacter jejuni e Campylobacter coli, descritos por Asakura et al. (2008).

\begin{tabular}{|c|c|c|c|}
\hline Primer & Sequência & & Pares de bases \\
\hline \multicolumn{4}{|l|}{$\operatorname{cdt} A$} \\
\hline CjspAU2 & 5'-AGGACTTGAACCTACTTTTC-3' & C. jejuni & 631 \\
\hline CjspAR2 & 5'-AGGTGGAGTAGTTAAAAACC-3' & & \\
\hline CcspAU1 & 5'-ATTGCCAAGGCTAAAATCTC-3' & C. coli & 329 \\
\hline $\begin{array}{l}\text { CespAR1 } \\
\text { cdtB }\end{array}$ & 5'-GATAAAGTCTCCAAAACTGC-3' & & \\
\hline CjSPBU5 & 5'-АТСТTTTAАССТTGCTTTTGC-3' & C. jejuni & 714 \\
\hline CjSPBR6 & 5'-GCAAGCATTAAAATCGCAGC-3' & & \\
\hline CcSPBU5 & 5'-TTTAATGTATTATTTGCCGC-3' & C. coli & 413 \\
\hline $\begin{array}{l}\text { CcSPBR5 } \\
\text { cdtC }\end{array}$ & 5’-TCATTGCCTATGCGTATG-3' & & \\
\hline CjspCU1 & 5'-TTTAGCCTTTGCAACTCCTA-3' & C. jejuni & 524 \\
\hline CjspCR2 & 5'-AAGGGGTAGCAGCTGTTAA-3' & & \\
\hline CcspCU1 & 5'-TAGGGATATGCACGCAAAAG-3' & C. coli & 313 \\
\hline CcspCR1 & 5'-GCTTAATACAGTTACGATAG-3' & & \\
\hline
\end{tabular}

A análise do produto amplificado para os Multiplex de $C$. jejuni e $C$. coli seguiu os mesmos procedimentos empregados para os genes hip e da aspartoquinase.

\section{RESULTADOS E DISCUSSÃO}

Campylobacter spp. foi isolado de $31(15,9 \%)$ amostras, sendo $29(93,6 \%)$ de amostras de suabe retal, um $(3,2 \%)$ de suabe de carcaça e um $(3,2 \%)$ de linfonodo. (Tab. 2). Das amostras de suabe retal, $26 / 29(89,6 \%)$ foram positivas para Campylobacter coli e 3/29 (10,4\%) para $C$. jejuni. Nas amostras de suabe de carcaça e de linfonodo, foi isolada somente a espécie Campylobacter coli.

Todas as 31 estirpes de Campylobacter spp. isoladas e identificadas bioquimicamente foram confirmadas como Campylobacter jejuni ou Campylobacter coli pela pesquisa dos genes da hipuricase e da aspartoquinase, respectivamente, 
amplificando fragmentos de $735 \mathrm{pb}$ e $500 \mathrm{pb}$ na PCR (Tab. 2). As 28 estirpes de Campylobacter coli identificadas foram positivas para a detecção dos genes da toxina CDT, sendo que no abatedouro A foram isoladas 9/45 (20\%) amostras que continham estirpes portadoras dos genes da toxina, e no abatedouro B 19/135 $(14,1 \%)$ estirpes positivas.
Em 26 estirpes originárias do reto, da carcaça e do linfonodo, foi possível detectar os três genes simultaneamente ( $c d t A, c d t B$ e $c d t C$ ), e em duas estirpes (R53 e R56) provenientes de suabe retal apenas os genes $c d t A$ e $c d t C$ (Fig. 1 e 2). As três estirpes de $C$. jejuni isoladas de suabe retal foram negativas para a detecção dos três genes, ou seja, não possuem os genes responsáveis pela produção da toxina CDT.

$c d t B 413 \mathrm{pb}$ cdtA $329 \mathrm{pb}$

$\begin{array}{lllllllllllll}\text { M } & \text { C38 } & \text { L55 } & \text { R2 } & \text { R3 } & \text { R8 } & \text { R9 } & \text { R10 } & \text { R11 } & \text { R12 } & \text { R13 } & +\end{array}$

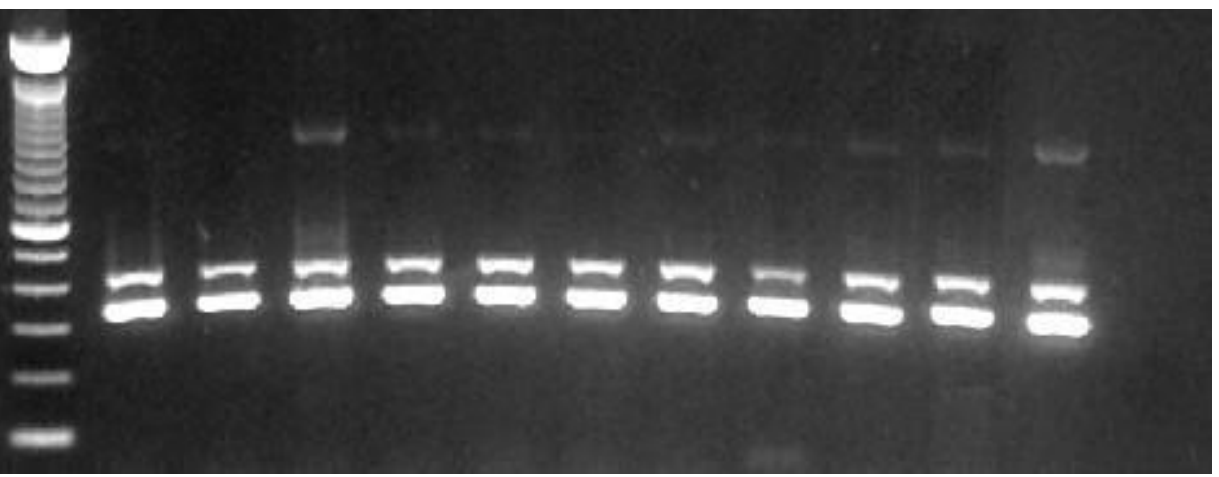

Figura 1. Resultados obtidos pela amplificação por Multiplex-PCR para deteç̧ão dos genes da toxina CDT ( cdtA e cdtB) de estirpes de Campylobacter coli. M: marcador de peso molecular (100bp Ladder Invitrogen); C38, L55, R2, R3, R8, R9, R10, R11, R13: estirpes de Campylobacter coli.; + controle positivo (C. coli CDC A3315); - controle negativo.

$c d t B 413 \mathrm{pb}$

cdtC $313 \mathrm{pb}$
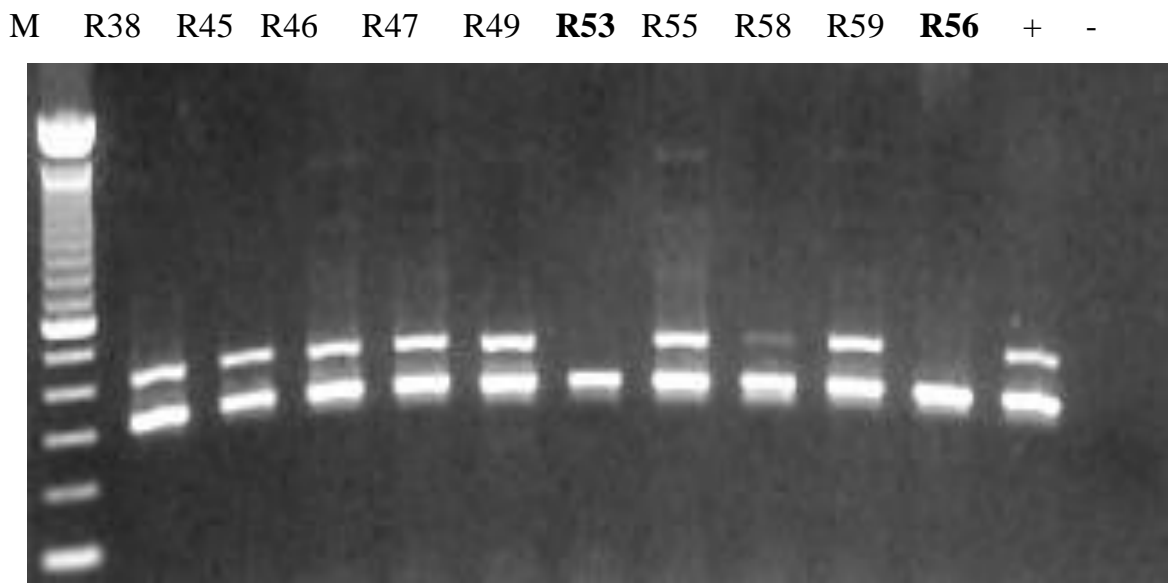

Figura 2. Resultados obtidos pela amplificação por Multiplex-PCR para deteç̧ão dos genes da toxina CDT ( $c d t B$ e $c d t C$ ) de estirpes de Campylobacter coli. M: marcador de peso molecular (100bp Ladder Invitrogen); R38, R45, R46, R47, R49, R53, R55, R58, R59, R56: estirpes de Campylobacter coli.; + controle positivo (C. coli CDC A3315); - controle negativo. 
Detecção de fatores de virulência...

Tabela 2. Classificação das estirpes isoladas de Campylobacter spp. quanto à origem, identificação, detecção dos genes do complexo $c d t$ e susceptibilidade aos antibióticos

\begin{tabular}{|c|c|c|c|c|c|c|c|}
\hline \multirow{2}{*}{$\begin{array}{l}\text { Denominação } \\
\text { da estirpe }\end{array}$} & \multirow{2}{*}{$\begin{array}{l}\text { Origem da } \\
\text { amostra }\end{array}$} & \multirow[t]{2}{*}{ Espécie identificada } & \multirow{2}{*}{$\begin{array}{l}\text { Gene } \\
c d t A\end{array}$} & \multirow{2}{*}{$\begin{array}{l}\text { Gene } \\
c d t B\end{array}$} & \multirow{2}{*}{$\begin{array}{l}\text { Gene } \\
c d t C\end{array}$} & \multicolumn{2}{|c|}{$\begin{array}{c}\text { Perfil de susceptibilidade } \\
\text { aos antibióticos }\end{array}$} \\
\hline & & & & & & A. Nal. & Cef. \\
\hline $\mathrm{R} 2$ & Suabe retal & Campylobacter coli & + & + & + & $\mathrm{R}$ & $\mathrm{R}$ \\
\hline R3 & Suabe retal & Campylobacter coli & + & + & + & $\mathrm{R}$ & $\mathrm{R}$ \\
\hline $\mathrm{R} 8$ & Suabe retal & Campylobacter coli & + & + & + & $\mathrm{R}$ & $\mathrm{R}$ \\
\hline R9 & Suabe retal & Campylobacter coli & + & + & + & $\mathrm{R}$ & $\mathrm{R}$ \\
\hline $\mathrm{R} 10$ & Suabe retal & Campylobacter coli & + & + & + & $\mathrm{R}$ & $\mathrm{R}$ \\
\hline $\mathrm{R} 11$ & Suabe retal & Campylobacter coli & + & + & + & $\mathrm{R}$ & $\mathrm{R}$ \\
\hline $\mathrm{R} 12$ & Suabe retal & Campylobacter coli & + & + & + & $\mathrm{R}$ & $\mathrm{R}$ \\
\hline $\mathrm{R} 13$ & Suabe retal & Campylobacter coli & + & + & + & $\mathrm{R}$ & $\mathrm{R}$ \\
\hline $\mathrm{R} 15$ & Suabe retal & Campylobacter coli & + & + & + & $\mathrm{R}$ & $\mathrm{R}$ \\
\hline R19 & Suabe retal & Campylobacter jejuni & - & - & - & $\mathrm{S}$ & $\mathrm{R}$ \\
\hline $\mathrm{R} 21$ & Suabe retal & Campylobacter jejuni & - & - & - & $\mathrm{S}$ & $\mathrm{R}$ \\
\hline $\mathrm{R} 25$ & Suabe retal & Campylobacter jejuni & - & - & - & $\mathrm{S}$ & $\mathrm{R}$ \\
\hline $\mathrm{R} 31$ & Suabe retal & Campylobacter coli & + & + & + & $\mathrm{S}$ & $\mathrm{R}$ \\
\hline R32 & Suabe retal & Campylobacter coli & + & + & + & $\mathrm{S}$ & $\mathrm{R}$ \\
\hline R33 & Suabe retal & Campylobacter coli & + & + & + & $\mathrm{R}$ & $\mathrm{R}$ \\
\hline R37 & Suabe retal & Campylobacter coli & + & + & + & $\mathrm{S}$ & $\mathrm{R}$ \\
\hline R38 & Suabe retal & Campylobacter coli & + & + & + & $\mathrm{S}$ & $\mathrm{R}$ \\
\hline $\mathrm{R} 45$ & Suabe retal & Campylobacter coli & + & + & + & $\mathrm{S}$ & $\mathrm{R}$ \\
\hline $\mathrm{R} 46$ & Suabe retal & Campylobacter coli & + & + & + & $\mathrm{S}$ & $\mathrm{R}$ \\
\hline R47 & Suabe retal & Campylobacter coli & + & + & + & $\mathrm{S}$ & $\mathrm{R}$ \\
\hline R49 & Suabe retal & Campylobacter coli & + & + & + & $\mathrm{S}$ & $\mathrm{R}$ \\
\hline R53 & Suabe retal & Campylobacter coli & + & - & + & $\mathrm{R}$ & $\mathrm{R}$ \\
\hline R55 & Suabe retal & Campylobacter coli & + & + & + & $\mathrm{S}$ & $\mathrm{R}$ \\
\hline R56 & Suabe retal & Campylobacter coli & + & - & + & $\mathrm{R}$ & $\mathrm{R}$ \\
\hline R58 & Suabe retal & Campylobacter coli & + & + & + & $\mathrm{S}$ & $\mathrm{R}$ \\
\hline R59 & Suabe retal & Campylobacter coli & + & + & + & $\mathrm{S}$ & $\mathrm{R}$ \\
\hline R61 & Suabe retal & Campylobacter coli & + & + & + & $\mathrm{S}$ & $\mathrm{R}$ \\
\hline R63 & Suabe retal & Campylobacter coli & + & + & + & $\mathrm{R}$ & $\mathrm{R}$ \\
\hline R65 & Suabe retal & Campylobacter coli & + & + & + & $\mathrm{S}$ & $\mathrm{R}$ \\
\hline C38 & Suabe de carcaça & Campylobacter coli & + & + & + & $\mathrm{S}$ & $\mathrm{R}$ \\
\hline L55 & Linfonodo & Campylobacter coli & + & + & + & $\mathrm{S}$ & $\mathrm{R}$ \\
\hline ATCC 33291 & (controle) & Campylobacter jejuni & + & + & + & $\mathrm{S}$ & $\mathrm{R}$ \\
\hline CDC A3315 & (controle) & Campylobacter coli & + & + & + & $\mathrm{S}$ & $\mathrm{R}$ \\
\hline
\end{tabular}

Positivo (+); negativo (-); R (suabe retal); C (suabe de carcaça); L (linfonodo mesentérico);

A. Nal. (ácido nalídíxico); Cef. (cefalotina)

Para a plena atividade da toxina, é necessária a presença dos três genes simultaneamente (Asakura et al., 2007); ou seja, no presente estudo, as estirpes de $C$. coli com ausência do gene $c d t B$, provavelmente, não possuem a atividade da toxina CDT. Asakura et al. (2007) sugeriram que mutações nos genes $c d t$, como deleção, inserção ou substituição de nucleotídeos, podem afetar a atividade da toxina.

As bactérias da família Campylobacteraceae, por sua natureza microaerófila, não são normalmente pesquisadas nos laboratórios de rotina, o que agrega mais um fator limitante para seu isolamento e estudo da epidemiologia de diferentes espécies e subtipos do gênero Campylobacter (Giacoboni et al., 2005; Gillespie et al., 2007; Scarcelli et al., 2009).
Segundo trabalhos publicados no Brasil e em outros países, frangos de corte e suínos são as mais importantes fontes de infecção de Campylobacter spp. para o homem, destacandose a espécie suína para o $C$. coli e os frangos de corte para o C. jejuni (Lander, 1985; Scarcelli et al., 1998; Gillespie et al., 2002; Calil et al., 2008; Scarcelli et al., 2009), como observado no presente estudo, em que prevaleceu a espécie C. coli em 28/31 estirpes isoladas de Campylobacter spp. $(90,3 \%)$ em relação ao $C$. jejuni $(9,7 \%$ - 3/31).

Segundo Malakauskas et al. (2005), diferentemente dos frangos de corte, as carcaças de suínos não são frequentemente contaminadas, com índices variando entre $2,9 \%$ e $10,3 \%$, dado semelhante ao observado no presente estudo, em que 1/65 (1,5\%) das carcaças de suínos foi positiva para $C$. coli. 
Durante o resfriamento e a secagem da carcaça de suínos, ocorre drástica diminuição do número de células viáveis de Campylobacter spp., o que não se verifica na carcaça de frango. Isto poderia ser explicado pelo fato de o processo de resfriamento de carcaça de frango ser mais rápido, cerca de uma hora contra até 24 horas em suínos. Além disso, deve ser considerada a diferença de textura da pele de frango, a qual apresenta poros que impedem a secagem total; enquanto a de suínos, sendo lisa, fornece menor proteção à dessecação (Lander, 1995). No entanto, a frequência de positividade de amostras nas fezes de suínos pode ser mais elevada do que nas fezes de frangos (Scarcelli et al., 1998).

O papel da espécie suína como potencial transmissora das campilobacterioses intestinais também está relacionado a hábitos alimentares regionais, em que se pratica a ingestão de embutidos suínos fabricados com intestinos submetidos à salga; ou ainda de carne suína crua ou malcozida (Lander, 1995; Scarcelli et al., 1998).

No presente estudo, verificou-se que 13/28 (21,5\%) estirpes de C. coli apresentaram resistência ao ácido nalidíxico (Tab. 2), em especial todas as isoladas do abatedouro A e quatro do abatedouro $\mathrm{B}$, demonstrando que o uso de antibióticos nestes animais, seja como uso terapêutico ou na ração como probiótico, pode interferir na seleção de estirpes resistentes e, portanto, alterar o padrão de antibiograma utilizado usualmente na classificação das espécies de Campylobacter.

Resultados semelhantes foram relatados por Campos (2007), o qual observou que 19,16\% (23/120) das estirpes de $C$. coli isoladas de fezes de carcaças de abatedouros do estado de São Paulo também apresentaram resistência ao ácido nalidíxico.

Estes achados reforçam a importância da confirmação genotípica das espécies, sendo de grande relevância a confirmação da espécie $C$. coli pelo gene da aspartoquinase e da espécie $C$. jejuni pelo gene da hipuricase, o que auxilia na diferenciação definitiva destas estirpes resistentes ao ácido nalidíxico da espécie Campylobacter lari, que é normalmente resistente à cefalotina e ao ácido nalidíxico.
Pela técnica de Multiplex-PCR foi detectada, pela primeira vez no estado de São Paulo, a presença do complexo de genes $c d t$ em $100 \%$ das estirpes de Campylobacter coli provenientes de suínos abatidos em frigoríficos. Tal fato configura os suínos como uma fonte potencial de disseminação de estirpes virulentas de Campylobacter coli, tanto para os trabalhadores dos frigoríficos como para os consumidores das carcaças e subprodutos.

\section{REFERÊNCIAS}

AGÊNCIA Paulista de Tecnologia dos Agronegócios (APTA). Setor de suínos e aves lidera crescimento nas exportações do agronegócio paulista. 2009. Disponível em:

<http://www.apta.sp.gov.br/noticias.php?id=3133>. Acesso em: fev. 2009.

ALTEKRUSE, S.F. Campylobacter jejuni in foods. $J$. Am. Vet. Med. Assoc., v.213, p.1734-1735, 1998.

ASAKURA, M.; SAMOSORNSUK, W.; TAGUCHI, M. et al. Comparative analysis of citolethal distending toxin (cdt) genes among Campylobacter jejuni, C. coli and C. fetus strains. Microb. Pathog., v.42, p.174-183, 2007.

ASAKURA, M.; SAMOSORNUK W.; HINENOYA, A. et al. Development of a cytolethal distending toxin (cdt) gene-based species-specific multiplex PCR assay for the detection and identification of Campylobacter jejuni, Campylobacter coli and Campylobacter fetus. FEMS Immun. Med. Microbiol., v.52, p.260-266, 2008.

BRASIL. Ministério da Saúde. Secretaria de Vigilância em Saúde. Coordenadoria de Vigilânciadas /doenças de Transmissão Hídrica e Alimentar. Análise Epidemiológica dos Surtos de Doenças Transmitidas por Alimentos no Brasil. 2008. Disponível em: <http://portal.saude.gov.br/portal/arquivos/pdf/DTA.p df.> Acesso em: 22 fev. 2011.

CALIL, R.M.; SCARCELLI, E.; MODELLI, K.D. et al. Campilobacterioses: o agente, a doença e a transmissão por alimentos. São Paulo: R.M. Calil, 1nd ed., 2008. 129p.

CAMPOS, F.R. Isolamento e caracterização de Campylobacter spp. em amostras de fezes e carcaças de suínos provenientes de abatedouros do Estado de São Paulo. 2007. 47f. Dissertação (Mestrado em Medicina Veterinária) - Faculdade de Medicina Veterinária e Zootecnia, Universidade de São Paulo, São Paulo. 
GABRIEL, M.R.; MELO, R.T.; ROSSI, D.A. et al. Campylobacter spp. em linfonodos mesentéricos de suínos abatidos. PUBVET, Londrina, v.4, n.19, Ed. 124, Art. 840, 2010. Disponível em: http://www.pubvet.com.br/artigos_det.asp?artigo=721. Acesso em: 23/02/2011.

GIACOBONI, G.; ECHEVERRÍA, M.G.; PERFUMO, C. PCR-RFLP for Campylobacter jejuni subtyping. Rev. Arg. Microbiol., v.37, p.81-83, 2005.

GILLESPIE, I.A.; O'BRIEN, S.J.; FROST, J.A. et al. The campylobacter sentinel surveillance scheme collaborators. A Case-Case Comparison of Campylobacter coli and Campylobacter jejuni Infection: A Tool for Generating Hypotheses. Emerg. Infect. Dis., v.8, p.937-942, 2002.

KUMAR, A.; AGARWAL, R.K.; BHILEGAONKAR, K.N. et al. Occurrence of Campylobacter jejuni in vegetables. Int. J. Med. Microbiol., v.67, p.153-155, 2001.

LANDER, K.P. Campylobacter: Proceedings of a conference held in Brussels 17 and 18 january 1985. New Haw, Weibridge, Surrey, U.K. Ministry of Agriculture, Fisheries and Food. 1985, 145p.

LINTON, D.; LAWSON, A.J.; OWEN, R.J. et al. PCR detection, identification to species level, and fingerprinting of Campylobacter jejuni and Campylobacter coli direct from diarrheic samples. $J$. Clin. Microbiol., v.35, p.2568-2572, 1997.

MALAKAUSKAS, M.; JORGENSEN, K.; NIELSEN, E.M. et al. Isolation of Campylobacter spp. from a pig slaughterhouse and analysis of cross-contamination. Int. J. Med. Microbiol., v.108, p.295-300, 2005.

MARTINEZ, I.; MATEO, E.; CHURRUCA, E. et al. Detection of cdtA, cdtB, and cdtC genes in Campylobacter jejuni by multiplex PCR. Int. J. Med. Microbiol., v.296, p.45-48, 2006.

MATARAGAS, M.; SKANDAMIS, P.N.; DROSINOS, E.H. Risk profiles of pork and poultry meat and risk ratings of various pathogen/product combinations. Int. J. Food Microbiol., v.126, p.1-12, 2008 .

NCCLS - National Committee for Clinical Laboratory Standards. Methods For Dilution Antimicrobial Susceptibility Tests For Bacteria That Grow Aerobically: Approved Standard - Sixth Edition. NCCLS document M7-A6 (ISBN 1-56238486-4). v.23, 2003. Disponível em: <http://www.sbac.org.br/pt/pdfs/biblioteca/clsiOPAS M7-A6.pdf>. Acessado em: fev/2009.
NESBAKKEN, T.; ECKNER, K.; HOIDAL, H.K. et al. Occurrence of Yersinia enterocolitica and Campylobacter spp. in slaughter pigs and consequences for meat inspection slaughtering, and dressing procedures. Int. J. Food Microbiol., v.80, p.231-240, 2003.

OIE-World Organisation for Animal Health. Campylobacter jejuni and Campylobacter coli In: Manual of Diagnostic Tests and Vaccines for Terrestrial Animals, p.1185-1191, 2008. Disponível em: $<\mathrm{http} / / / \mathrm{www}$. oie.int/eng/normes/mmanual/2008/pd f/2.09.03_CAMPYLO.pdf $>$ Acesso em: fev. 2009.

PARK, S.F. The physiology of Campylobacter species and its relevance to their role as foodborne pathogens. Int. J. Food Microbiol., v.74, p.177-188, 2002.

PEYRAT, M.B.; SOUMET, C.; MARIS, P. et al. Phenotypes and genotypes of campylobacter strains isolated after cleaning and disinfection in poultry slaughterhouses. Vet. Microbiol., v.128, p.313-326, 2008.

SAITO, S.; YATSUYANAGI, J.; HARATA, S. et al. Campylobacter jejuni isolated from retail poultry meat, bovine feces and bile, and human diarrheal samples in Japan: comparison of serotypes and genotypes. F.E.M.S. Immun. Med. Microbiol., v.45, p.311-319, 2005.

SCARCELLI, E.; GENOVEZ, M.E.; ROJAS, S. et al. Avaliação da presença de Campylobacter spp em suínos: sua relação com a ocorrência de distúrbios entéricos. Rev. Microbiol., v.22, p.112-115, 1991.

SCARCELLI, E.; GENOVEZ, M.E.; CARDOSO, M.V. et al. Avaliação do potencial de disseminação de Campylobacter spp por diferentes espécies animais. Arq. Inst. Biol., v.65, p.55-61, 1998.

SCARCELLI, E.; MIYASHIRO, S.; CAMPOS, F.R. et al. Detecção de Campylobacter jejuni em carcaças e cortes de frangos pela Reação da Polimerase em Cadeia. Rev. Hig. Alimentar, v.19, p.71-76, 2005.

SCARCELLI, E.; PIATTI, R.M.; HARAKAVA, R. et al. Use of PCR-RFLP of the fla A gene for detection and subtyping of Campylobacter jejuni strains potentially related to Guillain-Barré syndrome, isolated from humans and animals. Braz. J. Microbiol., v.40, p.952 -959, 2009. 